

\title{
O Desenvolvimento do Ecoturismo dentro do Parque Nacional da Chapada dos Veadeiros-GO
}

\author{
The Development of Ecotourism within the Chapada dos Veadeiros National Park-GO
}

\author{
Aline Alves Ribeiro ${ }^{1}$ \\ Thamyris Carvalho Andrade ${ }^{2}$
}

\footnotetext{
${ }^{1}$ Graduanda do Curso de Turismo Patrimonial e Socioambiental da Universidade Federal do Tocantins, Câmpus de Arraias "Prof. Dr. Sérgio Jacintho Leonor" e Poetisa. Email: alialvesribeiro@gmail.com

${ }^{2}$ Mestre em Turismo pela Universidade de Brasília - UNB no Centro de Excelência em Turismo - CET (2014). Especialista em Hotelaria pela Universidade On-Line de Viçosa e Bacharel em Turismo com ênfase em Ecoturismo pela Faculdade Integrada da Terra de Brasília-FTB (2008). Atualmente é Professora Assistente na Universidade Federal do Tocantins - UFT, no curso de Turismo Patrimonial e Socioambiental. É Pós graduanda em Sociobiodiversidade e Sustentabilidade no Cerrado pelo Centro UnB Cerrado, com obtenção de título para agosto de 2017. Trabalha com os temas: Turismo em Áreas Naturais (visitação, conservação ambiental, áreas protegidas, monitoramento, sustentabilidade e gestão ambiental); Hotelaria (Alimentos \& Bebidas e Governança) e Eventos (Docência e Produção). Email: thamyris.andrade@gmail.com
} 


\section{RESUMO}

A temática deste artigo está voltada para o desenvolvimento do Ecoturismo dentro do Parque Nacional da Chapada dos Veadeiros, em Alto Paraíso de Goiás-GO, aqui se restringirá apenas ao território que fica no entorno do escritório sede deste Parque, tendo sua entrada na Vila de São Jorge, distrito de Alto Paraíso. Assim este artigo tem por objetivo mostrar as modalidades existentes dentro desta atividade analisada e o seu funcionamento baseando-se na forma como é descrita na prática do Ecoturismo. A metodologia usada nesse processo foi a observação in loco do Território do Parque Nacional da Chapada dos Veadeiros entorno do seu escritório, com nota nos atrativos que são abertos a visitação e pesquisas exploratórias bibliográficas e em sítios na internet sobre a prática do Ecoturismo dentro deste Parque.

Palavras-Chave: Turismo. Ecoturismo. Chapada dos Veadeiros.

\section{ABSTRACT}

The theme of this article is focused on the development of Ecotourism within the Chapada dos Veadeiros National Park, in Alto Paraíso de Goiás-GO, here it will be restricted only to the territory that is around the headquarters office of this Park, having its entrance in the Village of São Jorge, district of Alto Paraíso. Thus, this article aims to show the existing modalities within this analyzed activity and its functioning based on the way it is described in the Ecotourism practice. The methodology used in this process was the in loco observation of the Territory of the National Park of Chapada dos Veadeiros surroundings of his office, with note in the attractions that are open to visitation and exploratory bibliographical researches and in Internet sites on the practice of Ecotourism within this Park.

Keywords: Tourism. Ecotourism. Veadeiros Plateau.

\section{Introdução}

A temática deste artigo está voltada para o desenvolvimento do Ecoturismo dentro do Parque Nacional da Chapada dos Veadeiros, em Alto Paraíso de Goiás-GO, como mencionado iremos restringir apenas ao território que fica no entorno do escritório sede deste Parque, tendo sua entrada na Vila de São Jorge, distrito de Alto Paraíso. Bem como tem por objetivo mostrar as modalidades existentes dentro desta atividade analisada e o seu funcionamento baseando-se na forma como é descrita da prática do Ecoturismo.

A metodologia usada nesse processo foi a observação in loco nos limites do Parque Nacional da Chapada dos Veadeiros no entorno do seu escritório, com nota nos atrativos que são abertos a visitação, que são eles: a trilha da Seriema, a trilha dos Cânions e Cariocas, a trilha dos Saltos e Corredeiras, parte da trilha das Sete quedas. Além da observação no atrativo do Carrossel, que está em fase de organização da sua infraestrutura para receber visitantes ${ }^{2}$. Além do embasar em pesquisas exploratórias bibliográficas, em sítios na internet de forma descritiva.

Nesta discussão será feito uma conexão geral de como o Turismo é entendido com base no que se pode observar em âmbito regional bem como nacional, assim como o planejamento do mesmo e os seus impactos, logo depois utilizaremos essas informações e contexto para discorrer sobre a prática do Ecoturismo dentro deste Parque. Desse modo serão analisadas duas concepções:

\footnotetext{
${ }^{2}$ Cada uma dessas trilhas será apresentada de forma individual no decorrer do artigo.
} 
1-A compreensão adotada por Turismo que parte de uma análise apenas mercadológica, tratando-o apenas como uma indústria que explora e destrói o meio ambiente, descartando todos os outros itens que se associam com a prática dessa atividade, e 2- O Turismo como um fenômeno sociocultural que envolve pessoas e engloba troca de experiências e conhecimento de outras culturas e hábitos. Nessa perspectiva geral da primeira compreensão o Turismo é visto como uma atividade sem respeito que apenas vende produtos, explora, exclui e degrada. Neste artigo adotaremos a segunda compreensão, que o vê como um fenômeno.

Na maioria dos casos o Turismo é planejado apenas por políticos e empresários interessados em abrir negócios, deixando assim em suas mãos a decisão de toda uma comunidade e seus anseios. Essa é uma alternativa limitada, pois a atividade já se inicia com um olhar ou visando beneficiar apenas alguns setores e/ ou pessoas, deixando de lado a ideia de integração e construção conjunta da efetivação do Turismo, onde se vê como umas das partes fundamentais deste processo, como cita Barretto (1991) apud Binfaré et al, p.30, 2014 como o planejamento do Turismo sendo exigido com uma "maior sistêmica, além de requerer pesquisa social, construção de equipamentos e oferta turística".

Com esse tipo de planejamento a prática do Turismo fica mais vulnerável a obtenção de resultados/impactos negativos. Os impactos gerados pelo Turismo podem ser subdivididos em algumas esferas, como sociais, culturais, econômicas e ambientais, tais itens correspondem aos pilares da sustentabilidade que como cita Elkington ${ }^{3}$ (1994) apud Sartori, Latrônico e Campos p.2 §1 (2014): “a sustentabilidade é o equilíbrio entre os três pilares: ambiental, econômico e social”. Tais impactos podem ser positivos ou negativos, para tanto é preciso se trabalhar almejando um Turismo com mínimo impacto, que degrade menos, que seja sustentável.

Depois dessa visão geral de como o Turismo é visto, da importância do seu planejamento e como na prática a maioria dos casos realmente trabalhados, bem como a abrangência dos seus impactos; será entendido como todo esse processo deveria ocorrer.

O Turismo pensado como sendo um fenômeno social complexo que envolve pessoas em uma troca de experiências no decorrer do seu deslocamento, pode ser produtor dos pilares da sustentabilidade, pois o mesmo envolve pessoas ${ }^{4}$, economia e utiliza o meio ambiente, derivando como mostra Januário apud Junior 2003 em "relações psicossociais onde também envolve a mercadização de produtos, na maioria não tangível, como no caso das paisagens" (Januário ([199-], p. 15) apud Junior, 2003).

Porém, também se vê como uma atividade que mal elaborada pode causar efeito contrário, por isso a importância que se tem de pensar o Turismo em todos os seus aspectos, até mesmo nos próprios turistas, pois conforme Coriolano, 2008 expõe: "os turistas buscam paisagens, cultura, patrimônio histórico e tudo

\footnotetext{
3 John Elkington foi descrito pela Business Week, como o "decano do movimento da sustentabilidade corporativa há três décadas." Disponível no site de busca do google.com.

${ }^{4}$ Neste envolver de pessoas diferentes, o Turismo engloba culturas, exercendo um desenvolvimento social cheio de subjetividades e troca de experiências, anseios e desejos.
} 
que faz parte dos ambientes, dos lugares, território e de tudo que essa atividade se apropria" (Coriolano e Leitão, p.468 2008).

De tal forma todas estas questões envolve uma base de planejamento sustentável que vise interagir a comunidade no contexto em que a atividade está inserida ou irá inserir, criando políticas públicas para que esse crescimento aconteça de forma integralizada e multiplicadora.

O Turismo praticado em áreas naturais tem uma função de cuidado maior ainda, pois ele envolve pessoas e pode degradar o meio. Assim ele deve interferir na manutenção e proteção ambiental no sentido de cuidar, educar e ensinar a preservar e cuidar; essa deve ser uma das funções educativas do Turismo quanto aos recursos naturais. E se tratando principalmente dessa causa, o Turismo praticado em áreas ambientais possui essa missão.

Dessa forma, o planejamento do Turismo deve levar em considerações os fatores de desenvolvimento, a localidade; deve se pensar em educação, desenvolvimento e menos degradação. Para que assim ocorra; é necessário: gestão pública, moradores, empresários, investidores etc.; e todos trabalharem na mesma direção. Assim poderemos ter uma boa política baseada em uma construção unânime, apresentando chances de propor e trazer melhoria local.

Todos esses itens relacionados serão percebidos em fases dentro da área de estudo, que é o Parque Nacional da Chapada dos Veadeiros, na qual já possui uma organização para recepção de visitantes e atividades que propiciem o contato com a natureza, onde parte do objetivo do artigo que é mostrar e evidenciar as possiblidades dessas atividades desenvolvidas e a prática do ecoturismo.

\section{Turismo Sustentável}

o "Turismo sustentável é aquele que busca minimizar impactos negativos ambientais e socioculturais, ao mesmo tempo em que promove benefícios econômicos para as comunidades locais e destinos" ${ }^{5}$. De acordo com Instituto Ecobrasil, este termo foi adotado pelo mesmo após as definições de Turismo Sustentável e Ecoturismo estabelecido pelo Acordo de Mohonk no ano de 2000.

Da mesma forma algumas empresas já começaram a adotar este conceito e a trabalhar nos seus conformes, como exemplo a Empresa Korubo que por base no Programa de Certificação em Turismo Sustentável ${ }^{6}$, acredita que "o novo paradigma do Turismo Sustentável considera a autenticidade cultural, a inclusão social, e a qualidade dos serviços, como peças fundamentais para viabilidade economia do Turismo a longo prazo" ${ }^{\prime 7}$.

Nesse sentido quando tratamos de Turismo sustentável, acreditamos que independente da segmentação criada para o mercado, todas as atividades que fazem jus a Turismo devem ocorrer de forma

\footnotetext{
${ }^{5}$ Disponível no site: www.InstitutoEcoBrasil.com.br acesso em 15 de maio de 2017 as $15 \mathrm{~h} 40 \mathrm{~min} \mathrm{~h}$.

${ }^{6}$ Realizado pelo Ministério do Turismo em Parceria com o Instituto de Meios de Hospedagem durante 2002 a 2007. Infelizmente não deve muito sucesso, o objetivo do programa era de cadastrar mais de 400 empreendimentos no país, porém teve alcance apenas de 10 empreendimentos cadastrados. (Disponível em JORNAL AGENDA BAHIA, 2014).

${ }^{7}$ Disponível no sítio www.Korubo.com acesso em 15 de Maio de 2017, as 16h00minh.
} 
consciente e sustentável; sejam na Praia, em cachoeiras, centros rurais ou urbanos, com crianças ou adultos etc. A consciência e a sensibilização de praticar um Turismo sustentável, bem como de gerir um empreendimento que condicione tais pilares são fundamentais para alcançarmos um Turismo menos massificador e explorador dos recursos naturais e culturais.

Isso ainda se prioriza com mais ênfase atualmente principalmente por dois motivos que valem realçar, sendo eles: a busca maior pelos turistas por ter contato com a natureza, de ir para o interior, aproximar-se da cultura regional e comunidade local, isto se tem percebido com maior frequência até mesmo pelo direcionamento das propagandas, que estão divulgando com maior atenção tais locais que possuem recursos naturais.

O segundo motivo que se faz importante para essa crescente divulgação de Turismo sustentável é o fato que o ano de 2017 foi considerado pela Assembleia Geral 70 das Nações Unidas ${ }^{8}$, o Ano Internacional do Turismo Sustentável para o Desenvolvimento; que desencadeia em outras séries de motivos que se caracterizam como sendo essenciais para esta prática, pois temos acompanhando uma gama de informações que dizem respeito a sustentabilidade, no entanto, percebemos que tem se tornado apenas uma expressão de uso de marketing, onde na prática a teoria da sustentabilidade não se reproduz, isto por exemplo em vários empreendimentos.

A discordância do que é pregado não ser visto na prática nos leva a uma chance para aproveitarmos este ano como sensibilização que nos permita praticarmos o que tanto divulgamos e aprendemos. No que se multiplica a Turismo, usá-lo como forma de contribuição sustentável para o desenvolvimento, sendo que o Ecoturismo se apresenta como fonte principal para esta possibilidade.

Ainda se tratando de oportunidades para se efetivar o Turismo sustentável, temos também como proposta da ONU, a Agenda de Desenvolvimento Sustentável e os Objetivos do Desenvolvimento Sustentável que trabalham com base em princípios, políticas e práticas que compõem o comportamento do consumidor e de quem oferece ações que desenvolvam um Turismo sustentável; visando promover o papel do Turismo em cinco áreas, sendo elas econômica, social, proteção ao meio ambiente, a diversidade patrimonial e cultural e a sensibilização em prol da paz e da segurança ${ }^{9}$.

\footnotetext{
${ }^{8}$ A Assembleia Geral 70 das Nações Unidas aconteceu durante os dias 15 a 28 de setembro de 2015 na sede da ONU em Nova York, Estados Unidos disponível no site www.naçõesunidas.gov

${ }^{9}$ Disponível no site do Instituto EcoBrasil, www.Institutoecobrasil.com
} 
Desta forma, a ONU desenvolveu um sistema que se aplica o sentido da incorporação do desenvolvimento sustentável como pode ser analisado abaixo:

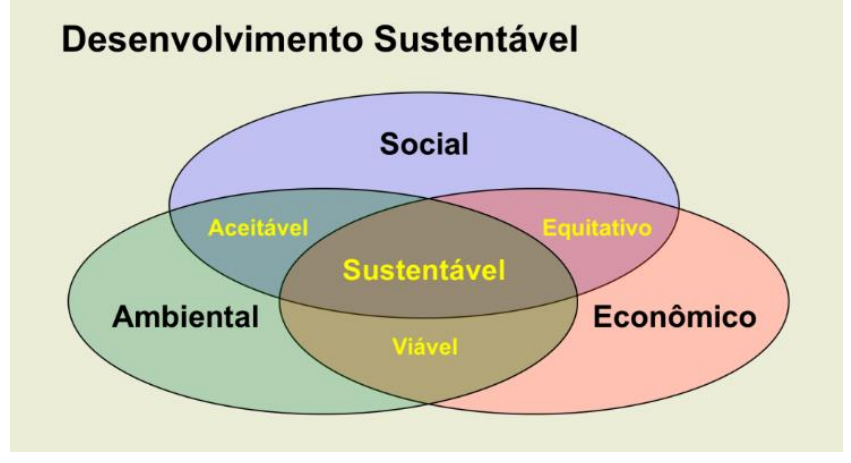

Fonte: INSTITUTO ECOBRASIL, 2015.

Esse sistema apresentado, nos mostra como deve funcionar o desenvolvimento sustentável dentro dos parâmetros da ação do Turismo. Trabalhando no sentido de ambos os lados no que se refere ao mercado, o consumidor e o ofertante.

Em influência da concepção que permeia esse carácter do Turismo consciente nos põe na responsabilidade de contribuímos para que ele aconteça na prática. Nesse sentido, o Ecoturismo tem a função educativa de fomentar a preservação do meio ambiente, por meio de ações coletivas no praticar dessa atividade.

Neste paralelo, o Conselho Nacional da Reserva da Biosfera da Mata Atlântica produz alguns princípios dentro dos parâmetros do Programa de Certificação de Turismo Sustentável, também inseridos aqui no Brasil pelo Conselho Brasileiro de Turismo Sustentável que julgam ser essenciais para que atividade se compreenda neste padrão. São eles:

- Respeitar a Legislação Vigente;

- Garantir os direitos das populações locais;

- Conversar o ambiente natural e sua biodiversidade;

- Considerar o patrimônio cultural e os valores locais;

- Estimular o desenvolvimento social econômico dos destinos turísticos;

- Garantir a qualidade dos produtos, processos e atitudes;

- Estabelecer o planejamento e a gestão responsáveis. ${ }^{10}$

São itens que ditam padrões que devem ser aderidos, principalmente em empreendimentos que queiram alcançar a certificação de sustentabilidade. Esses princípios nos fornece uma visão que compõem elementos básicos para começarmos a praticar um Turismo sustentável consciente.

\footnotetext{
${ }^{10}$ Dados retirados da Caderno $\mathrm{N}^{\circ} 30$ do Conselho Nacional da Reserva da Biosfera Mata Atlântica, 2004.
} 


\section{Turismo em Unidades de Conservação}

Os Parques Nacionais brasileiros, em sua maioria são abertos a visitantes, seja para atividades de pesquisa, para fins educativos, científicos, culturais, recreativos e também para fins turísticos (RUDZEWICZ e CASTROGIOVANNI, 2015).

Quando os Parques se responsabilizam em manter-se abertos para envolver o Turismo em suas atividades, eles permitem a população um meio de acesso maior nestes locais, além propiciar o desenvolvimento do local, também ajuda no exercer do empoderamento das famílias que residem no ambiente, ele ainda se mostra capaz de gerar emprego como cita Wearing e Neil (2001; p. 71) apud Rudzewicz e Castrogiovanni: "O Turismo em áreas de proteção pode trazer crescentes benefícios econômicos, tanto pelos gastos diretos dos turistas quanto pelas oportunidades de emprego que gera, seja dentro do parque ou em áreas adjacentes".

Esses empregos sendo diretos ou indiretos trazem uma amplitude de serviços como a necessidade de condutores locais para conduzirem os visitantes, bem como investimentos em empreendimentos e equipamentos se serviço de apoio ao Turismo. ${ }^{11}$ Todos agregando valor a produção local.

Para a construção de um Parque seja ele municipal, estadual ou Nacional é necessária uma maior atenção as comunidades locais, sejam elas ribeirinhas, quilombolas ou outras em geral, pois foram grupos que sobrevivem ali que possuem uma história de vida nas suas distintas gerações de familiares. Pois são essas pessoas que também vão ajudar na conservação do Parque e daquele meio envolvido.

Assim como para Boo 1992 apud Serrano 2001 in Rudzewicz e Castrogivanni; os Parques de modo geral fazem um elo entre integração com a comunidade, informação e educação ambiental, além da apropriação de mais espaços de lazer. Contribuindo assim para que o equilíbrio entre a conservação e o Turismo sejam encontrados.

No entanto, para isso acontecer é necessário um bom plano de manejo que vise um estudo de capacidade de carga, um projeto de infraestrutura que não degrade o meio ambiente, produção do lixo, e um dos pontos essenciais, o preparo por meio da educação ambiental dos visitantes ao entrarem em uma área ambiental, pois preparando-os teremos visitantes conscientes, evitando uma degradação maior do espaço protejido.

No decorrer deste processo é de suma importância a participação da comunidade nesta construção para que realmente o Turismo beneficie o local, e não uma porção de pessoas que residem no espaço; gerando desenvolvimento mútuo.

Neste contexto, o Ecoturismo enxergado como um Turismo de mínimo impacto, que promove a educação ambiental é uma ferramenta segmentária do Turismo que inclui a comunidade em seu processo como a autora Rudzewicz evidencia que "maioria dos autores como Kinker, Wearing e Neil, e outros, defendem o Ecoturismo como o segmento do Turismo adequado às áreas naturais protegidas", assim como

\footnotetext{
${ }^{11}$ Os empreendimentos e equipamentos de serviço do Turismo são os hotéis, pousadas, restaurantes, lanchonetes, centros de convenções, entre outros empreendimentos que apresentam apoio ao desempenhar da atividade turística.
} 
também expressa que para isso acontecer é necessário que se exista características intrínsecas e ações consciente e integrada dos agentes do desenvolvimento do Turismo.

Neste sentido, o Ecoturismo sendo uma prática característica nos parques, se propõem a uma tarefa que envolve a integração da comunidade em suas atividades e a conservação e proteção ao meio ambiente; fomentando a educação ambiental. Analisaremos nessa mesma perspectiva o Ecoturismo no Parque Nacional da Chapada dos Veadeiros.

\section{Parque Nacional da Chapada dos Veadeiros}

De acordo com os dados do Instituto Chico Mendes de Conservação da Biodiversidade, o ICMbio, o Parque Nacional da Chapada dos Veadeiros foi criado em 1961 pelo presidente da época Juscelino Kubitschek, protegendo uma parte da área que consiste o bioma cerrado, tendo seu nome inicial de Parque Nacional do Tocantins.

"Sua criação tinha como objetivo proteger áreas de admirável beleza, recursos hídricos e fauna e flora característicos do cerrado, protegendo principalmente o ponto culminante do Planalto Central". (ANDRADE, 2014)

O Parque resguarda uma área que antes era utilizado por várias famílias de garimpeiros, que faz parte da história local da região. Sendo que mesmo abriga diversas "formações vegetais, centenas de nascentes e cursos d'água e formações geológicas que ultrapassam um bilhão de anos" ${ }^{12}$.

Inicialmente o Parque foi criado para proteger uma área de 625 mil hectares, englobando as cidades de Cavalcante e Alto Paraíso de Goiás, porém por entraves políticos econômicos, na qual se dizem a respeito dos problemas advindos das desapropriações de terras para construção do Parque, essa área se reduziu a 171.924 ha. "Também em 1981 ele foi novamente reduzido a 65 mil hectares por conta do Projeto Agropecuários Alto Paraíso, que solicitava uma passagem da G0-239"13. No entanto, por uma luta que vários órgãos ambientais, Parques e a WWF apoiaram, além das milhares de pessoas que apoiaram a causa assinando a petição para o Amplia Veadeiros, o parque foi ampliado para 240.611ha, incluindo os municípios de São João da Aliança, Nova Roma, Teresina de Goiás (ICMbio,2017). Sendo uma grande conquista para a preservação e conservação do cerrado.

Como retrata a própria WWF, "o parque passa a proteger 34 espécies de animais ameaçados de extinção, como o lobo-guará e a onça pintada, pelo menos 17 espécies de plantas também ameaçadas, sendo que área abriga cerca de 600 nascentes que irão garantir a segurança hídrica para a região." (WWF Brasil, 2017). O decreto foi assinado no dia 05 de junho de 2017, em homenagem ao dia Mundial do Meio do Ambiente.

\footnotetext{
${ }^{12}$ Disponível no site do Instituto Chico Mendes de Conservação da Biodiversidade www.lcmbio.gov.br acesso 05 de junho de 2017, as $10 \mathrm{~h}$.

${ }^{13}$ Dados presentes retirados do site do ICMbio (www.icmbio.gov.br)
} 
CENÁRIO, Brasília, V.5, n.9 | 118-124 | Dez. 2017 | p. 118

No ano de 2001, o Parque Nacional da Chapada dos Veadeiros (PNCV ou Parna Veadeiros) foi declarado Patrimônio Natural da Humanidade pelo UNESCO. Com suas paisagens que retratam e resguardam as belezas do cerrado, o Parna Veadeiros chama atenção de pessoas de todas as partes Brasil e até do mundo, por isso a sua conservação se faz necessária. "Além da conservação, o parque tem como objetivos a pesquisa científica, a educação ambiental e a visitação pública". (BRASIL, 2006 p.11).

$\mathrm{O}$ acesso ao PNCV se faz pela BR-020 passando em sequência pelas rodovias GO-118 e GO-239, sua localização exata está na Vila de São de Jorge, que é um distrito de Alto Paraíso, sendo $26 \mathrm{~km}$ do mesmo. Para facilitar uma visão apurada de distância, o PNCV fica a $230 \mathrm{~km}$ de Brasília e 1.227km de São Paulo. 0 Parque fica aberto de Terça a domingo, sendo que as segundas só se abrem se for feriado, e se fecha no primeiro dia útil após o feriado; e no período das férias escolares (julho e Dezembro) este fica aberto dos os dias da semana.

O Parque Nacional da Chapada dos Veadeiros, assim como em alguns parques faz o uso do Serviço de Voluntariado, "implementando pelo ICMbio em 2009, na qual consiste na prática do trabalho voluntário em Unidades de Conservação, tendo como objetivo aproximar as pessoas enquanto sociedade destes Centros, bem como mostrar que este é um bem de todos", sendo cada um responsável pela conservação do mesmo. Os trabalhos feitos pelos voluntários estão divididos em administração pública do Parque; Uso Público e Negócios que trata diretamente com as visitações; Monitoramento da Biodiversidade, que é o desenvolver de observação de fauna e flora com fins de monitorar a biodiversidade do parque; e as tabulações de dados significativos para o Parque como quantidade de visitantes, de lixo nas trilhas e demais dados a cerca do monitoramento das quatro trilhas.

\section{4 [Os Atrativos] as trilhas do Parque Nacional da Chapada dos Veadeiros}

O PNCV possui quatro trilhas abertas a visitação que possibilita aos visitantes a chegada aos seus atrativos: Travessia das sete quedas, Cânions e Cariocas, Saltos e Corredeiras e a Seriema. Sendo locais que possibilitam a prática de "caminhadas, observação de fauna de flora, banho de rio e cachoeira, contemplação da paisagem e acampamento rústico" (Parna Veadeiros/ICMbio). Vejamos agora tais atrativos e suas características descritivas separadamente ${ }^{14}$.

Travessia das Sete quedas: Essa trilha possui uma extensão de aproximadamente $23 \mathrm{~km}$, tendo uma duração estimada de 2 a 3 dias, se o visitante optar por mais um dia acampado. Possui um nível de dificuldade considerado muito pesado, a sinalização para seguir esta trilha é cor das setas laranja; No início do percurso, o visitante deve seguir as setas vermelhas por $3 \mathrm{~km}$ e seguir a bifurcação à direita para a Travessia das Sete Quedas. A partir dali, as setas são na cor laranja. Chegando ao Cânion 1, há uma placa indicando o início da Travessia. A paisagem possui diversas fisionomias, como campos rupestres, veredas,

\footnotetext{
${ }^{14}$ Todos os dados inseridos a cerca das trilhas foram retirados do site do ICMbio/ Parque Nacional da Chapada dos Veadeiros/atrativos. (www.icmbio.gov.br)
} 
CENÁRIO, Brasília, V.5, n.9 | 119- 124 | Dez. 2017 | p. 119

além do cerrado strictu sensu até a primeira passagem do Rio Preto, onde deverá cruzar a diagonal formada pelos dois postes laranja, um em cada lado da margem. Até ali, o visitante percorreu $10 \mathrm{~km}$.

Após atravessar o rio, o visitante irá percorrer mais $7 \mathrm{~km}$ por uma trilha histórica da época do garimpo, conhecida como Fiandeiras, passando por campos sujos e limpos e adentrando pelo cerrado rupestre até chegar ao camping das Sete Quedas, próximo ao Rio Preto, com água de boa qualidade e capacidade para 30 visitantes por noite. Existe um banheiro seco localizado a 100 metros da área de camping. Siga a sinalização para encontrar o banheiro e as instruções para uso disponíveis no interior.

O Parque não fornece papel higiênico, álcool em gel e outros produtos de higiene. A partir do camping, a trilha continua margeando o rio Preto pelas pedras por cerca de 500 metros e o visitante deverá ficar atento às setas laranja que apontarão para o poste também laranja do outro lado do rio, indicando o melhor ponto da segunda passagem do Rio Preto. Depois, a trilha continua por pouco mais de $6 \mathrm{~km}$ pelo cerrado rupestre, passando pela torre da Mata Funda e finalizando na rodovia GO-239. A travessia termina fora do Parque Nacional, na beira da estrada, a cerca de $12 \mathrm{~km}$ de São Jorge e $24 \mathrm{~km}$ de Alto Paraíso. Portanto, o visitante deverá contratar por conta própria o serviço de traslado.

Trilha dos Saltos e Corredeiras: Possui uma extensão aproximada de $11 \mathrm{~km}$, ida e volta, o nível de dificuldade da trilha é dividida em duas, sendo que saltos e corredeiras têm nível pesado e apenas corredeiras tem nível moderado. A trilha está sinalizada por setas amarelas. O percurso é feito na maior parte do tempo em terreno acidentado e bastante pedregoso. Na ida, inclui a passagem pelo Garimpo, considerado o maior garimpo de cristal de quartzo da região quando estava em atividade (1912 a 1961). Nesta área do Parque são avistadas lindas veredas e tem-se uma bela noção do verdadeiro esplendor da Chapada dos Veadeiros. Depois de aproximadamente $4 \mathrm{~km}$ de caminhada, chega-se ao Mirante do Salto de $120 \mathrm{~m}$ do Rio Preto, ponto alto do percurso, de onde se vê a queda d'água do Rio Preto, de perder o fôlego. A 800 metros dali está o Salto de $80 \mathrm{~m}$, onde é possível tomar banho no rio, em área limitada devido ao nível da água.

Depois de uma subida bastante íngreme de cerca de 800 metros, que requer cuidados para pessoas com problemas respiratórios, hipertensão arterial e asmáticos, e mais 1,5 km de caminhada chega-se às Corredeiras do Rio Preto, onde também é possível tomar banho de rio, nas hidromassagens formadas em suas pequenas quedas. Há uma trilha suspensa de 230 metros para as Corredeiras com acessibilidade para pessoas com deficiência e mobilidade reduzida. A caminhada final até a portaria tem mais $3 \mathrm{~km}$, portanto, é preciso ficar atento com o horário de fechamento do Parque, às $18 \mathrm{~h}$.

Trilha dos Cânions e Cariocas: A extensão dessa trilha é de aproximadamente $12 \mathrm{~km}$, com nível de dificuldade moderado superior e as setas são de cor vermelha no decorrer da trilha. $O$ percurso é feito em trilha pedregosa, plana sem muitos aclives, passando por lugares com sombra, bicas com água e paisagens belíssimas. Após cerca de 5km de caminhada, chega-se a uma bifurcação. Seguindo à esquerda mais $1 \mathrm{~km}$, o caminho leva à Cachoeira da Carioca. À direita, por cerca de 800m, está o Cânion II. 
$\mathrm{Na}$ Cachoeira da Carioca o Rio Preto se divide em duas quedas. A descida até o poço é íngreme e requer atenção redobrada. Lembre-se: não se arrisque sem necessidade e se não estiver seguro. Voltando pelo mesmo caminho em meia hora de caminhada o visitante chegará ao Cânion II, por onde se atravessa blocos de pedra até chegar a um enorme poço para banho. Na época das chuvas, somente um pequeno trecho do poço é utilizado, devido à forte correnteza do Rio Preto. A caminhada final até a portaria tem cerca de 3,5 km de extensão.

Trilha da Seriema: Possui uma extensão aproximada de 800 m de ida e volta, com nível considerado muito leve e as suas setas são azuis. O percurso ocorre em terreno plano e bem marcado até chegar no córrego rodoviarinha, onde é possível tomar banho na época das chuvas. Esta trilha é recomendada para pessoas com dificuldade de locomoção, como idosos, grávidas e crianças.

Todas as trilhas que foram descritas acima mostram o potencial do Parque Nacional da Chapada dos Veadeiros para a prática do Ecoturismo, sendo que o próprio é muito procurado por pessoas que querem explorar e vivenciar esse contato com a natureza. Os próprios percursos das trilhas trazem a chance de vislumbrar paisagens que é de admirar os olhos e despertar sensações de cuidado, pertencimento e preservação nos visitantes.

De modo que o parque trabalha com a educação ambiental por meio de recursos audiovisuais assim que visitante chega ao próprio parque, sendo que o mesmo é destinado para uma sala de vídeo onde ali aprecia um videoclipe de cinco minutos. Neste vídeo, fala-se das quatro trilhas do parque, bem como dos cuidados que se deve ter e dicas para ter um bom passeio; em seguida o visitante deve assinar um termo de compromisso de normas e riscos, sendo o mesmo o único responsável pela sua segurança. Após estes procedimentos o visitante pode iniciar sua trilha tranquilamente, se atentando ao horário de saída que é até às 18 horas; sendo a entrada das 8:00h as 12:00h.

O parque possui uma trilha que ainda não está aberta a visitação, essa passa por uma fase de planejamento e estruturação; é a trilha do Carrossel, que em breve estará inclusa no roteiro de passeio pelo parque. Essa trilha conta com mirante de vista inacreditável da imensidão de águas da Chapada, bem como uma surpreendente visão das formações rochosas que abriga essa área. Será mais uma trilha para os ecoturistas se deleitarem, bem como todos visitantes de modo geral.

O Ecoturismo praticado no parque revela ser um Turismo de mínimo impacto desde o cuidado com a capacidade de carga de pessoas nos seus respectivos atrativos, bem como o cuidado em instruir os visitantes para não deixar lixo, sendo este um dos problemas de quase todos os lugares. O lixo encontrado nas trilhas é razoavelmente pouco pela quantidade de visitantes que passam por ali. Neste sentido o parque tem um serviço de monitoramento de trilhas, na qual os voluntários fazem coleta desse lixo e vistoriam se tem algum visitante comprometendo a ordem do lugar.

Praticam-se todos os cuidados necessários para que natureza seja cuidada e o visitante tenha uma boa experiência dentro parque, o estabelecimento de capacidade de carga é um dos quesitos que o Parque busca seguir. Cada trilha dentro do parque possui uma capacidade de carga de pessoas, capacidade 
considerada suficiente para que o lugar seja degradado em menor intensidade. Assim, está dividido que a Travessia das Sete Quedas possui capacidade de 30 pessoas acampadas/noite; a Trilha dos Saltos: 250 visitantes/dia; a Trilha dos Cânions: 200 visitantes/dia; a Trilha da Seriema: 30 visitantes/dia. Sendo que quando esses valores são alcançados não é permitida a entrada de mais nenhuma pessoa na trilhas (ICMbio).

\section{Visitação no Parque Nacional da Chapada dos Veadeiros}

“O parque recebe intensa visitação do estado de Goiás e Distrito Federal, mas é também um roteiro importante para visitantes nas regiões Sul e Sudeste." (BRASIL, 2006 p.12). O Parque possui as quatro trilhas abertas a visitação como foi visto acima, e em períodos de férias e feriados todas as trilhas atingem lotação máxima.

De modo que essas pessoas que visitam o parque, são atraídos em sua maioria pelas belas paisagens vistas pelos mesmos assim como a troca "de boca a boca" com amigos e conhecidos. Em uma das falas do Fernando Tatagiba, atual Chefe do Parque a uma entrevista ${ }^{15}$ ele evidencia justamente esse quesito dizendo que: "O turista que vem em busca de aventuras na unidade de conservação, utiliza vários serviços, hospeda-se nas pousadas vizinhas ao parque, consome nos restaurantes, bares e lojas e ainda divulga sua experiência para uma extensa rede de contatos. Isso traz outros turistas e a roda da economia se movimenta a partir dai". Essa fala esclarece e explica até certo ponto o grande número de visitantes que o parque recebe anualmente.

Para ilustrar esse crescimento elevado de visitantes, o gráfico abaixo mostra uma escala desde o ano de 2000 a 2016 e respectivamente os números de visitantes. Tais dados foram baseados no site do ICMbio, bem como Ministério do Meio Ambiente. Um dos pontos de interesse para essa ilustração é evidenciar a velocidade do aumento de visitantes, assim como realçar o grande número de visitantes no ano de 2016.

\footnotetext{
15 Entrevista feita com a WWF, disponível em http://www.wwf.org.br/informacoes/?uNewsID=53802 acesso ao dia 10 de junho de 2017 as $10: 45 \mathrm{~h}$.
} 
Agora com a Ampliação do Parque e com as novas possibilidades que a mesma trará, esses números continuarão a aumentar.

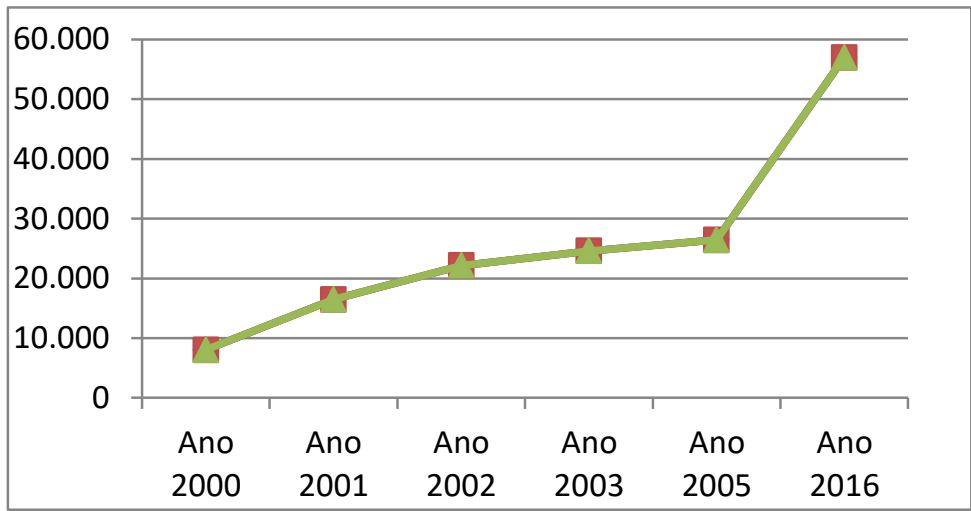

Fonte: a autora com base em dados do ICMbio.

Nesta perspectiva, é evidente a procura pelo destino da Chapada dos Veadeiros, sendo necessária uma continuação de estudos que mostrem esse potencial turístico e a importância de se cuidar para que o mesmo continue sendo esse espaço de prática de um Turismo de mínimo impacto, na qual consideramos aqui, Ecoturismo.

\section{Discussões e Considerações Finais}

A visitação nas Unidades de Conservação traz uma visão de se aproximar a sociedade da natureza por meio da prática do Ecoturismo, promovendo uma prática saudável e sustentável que busca preservar os recursos naturais e beneficia as comunidades locais do seu entorno.

"O Turismo, ao mesmo tempo em que fortalece a apropriação das unidades de conservação pela sociedade, dinamiza as economias locais e incrementa os recursos financeiros para a manutenção destas áreas." (BRASIL, 2006 p.2). Essa é a ideia que deve ser seguida na prática para que o Turismo seja realmente integrador e sustentável, de modo que também dinamize a economia do local.

Sendo este o principal desafio, pois desenvolver um Turismo responsável e integrado à diversidade sociocultural é uma atividade que demanda manter um equilíbrio entre economia e preservação do meio ambiente, sendo que mantendo esse equilíbrio entre essas balanças, tem-se uma chance maior de produzir uma prática de Ecoturismo de sucesso.

O Ecoturismo nas suas bases, como vimos, preocupa-se com a prática da educação ambiental ao colocar o homem em contato com a natureza, de modo que também se salienta uma preocupação e cuidado com a conservação da biodiversidade e os conhecimentos tracionais do lugar, bem como a sua cultura; preparando o mesmo para este contato.

Para Rudzewicz, Castrogiovanni, 2003, p. 6 "o Turismo também pode oferecer apoio adicional aos parques, na medida em que os divulga com expressividade por envolver milhares de pessoas neste processo e, com isso, atrair mais atenção dos governantes e políticos envolvidos para a sua situação", nesse 
sentido o Turismo por meio do Ecoturismo beneficia os parques e oportuniza uma proximidade da relação homem e natureza.

Porém é necessário cuidado, uma vez que quando se trata de unidades de conservação, deve se atentar se os visitantes não estão deixando essa área comprometida e modificando a paisagem, degradando-a, pois a função do Ecoturismo neste sentido é lutar por um Turismo de mínimo impacto que irá apoiar as causas de conservação.

Neste sentido, O Parque Nacional da Chapada Veadeiros tem uma visibilidade tamanha pelo seu número de visitantes, sendo que o mesmo se encontra em um estágio que busca envolver a comunidade no seu contexto econômico de modo geral; tendo que a comunidade da Vila de São Jorge, onde se localiza o parque tem em sua maioria a renda proveniente dos comércios da cidade feitos para atender a demanda turística e demais equipamentos de apoio ao Turismo.

Quanto ao Ecoturismo no parque, é uma atividade que vem crescendo cada vez mais, ainda que os homens dos grandes centros buscam fugir do caos e estresses que esses passam, e é essa busca pelo contato com a natureza que tem produzido o crescimento dessa atividade, principalmente no Parna Veadeiros. As proximidades do parque abrangem diversas atividades que deixam os visitantes "aliviados e descansados mentalmente", como yoga, caminhadas e spas ao ar livre, deixando os visitantes em maior sintonia com o meio ambiente com uma diversidade de opções.

Assim o PNCV se torna uma área de grande procura por esses amantes da natureza, ecoturistas em busca de descanso, contato e prazer com os ambientes naturais. Assim o desenvolvimento do Ecoturismo no Parque Nacional da Chapada dos Veadeiros ganhou popularidade e mais adeptos. Agora, com a ampliação, consequentemente essa demanda irá aumentar, portanto o parque e a comunidade devem se preparar para continuarem exercendo a prática do Ecoturismo tanto dentro da Unidade de Conservação como no seu entorno.

O Ecoturismo no Parque Nacional da Chapada dos Veadeiros apresenta-se como uma prática que está ajudando na preservação e divulgação da região, sendo necessário um planejamento sustentável para que essa área continue tendo sucesso nesse exercício. Desse modo a região continuará a ganhar com o Ecoturismo, e o mesmo terá um desenvolvimento cada vez mais eficiente.

\section{Referências}

ANDRADE, Thamyris Carvalho. A Experiência das Visitas Guiadas e Autoguiadas: Um Ensaio Interpretativo Pelo Parque Nacional da Chapada dos Veadeiros - Go/ Thamyris Carvalho Andrade, 2014.

BARRETO, 1991 in BINFARÉ, Paula Wabner et. al. Planejamento Turístico: Aspectos teóricos e conceituais e suas relações com o conceito de Turismo. Revista de Turismo Contemporâneo - RTC. Natal, v. 4, Ed. Especial, p. 24-40, abr. 2016.

BOO apud SERRANO, 2001 in RUDZEWICZ, Laura; CASTROGIOVANNI, Antonio Carlos. Desenvolvimento do Turismo de Aventura em Parques Nacionais Brasileiros. In: I SEMINTUR- Seminário de Pesquisa em Turismo do Mercosul, 2003. Caxias do Sul- RS: Universidade de Caxias do Sul, 2003. P.1-10. 
CENÁRIO, Brasília, V.5, n.9 | 124-124 | Dez. 2017 | p. 124

BRASIL, Ministério do Meio Ambiente, Ministério do Turismo e Instituto Chico Mendes da Conservação e Biodiversidade. Plano de Ação para Estruturação e Promoção do Turismo nos Parques Nacionais: Programa de Turismo em Parques. Revista final, 2006.

CONSELHO NACIONAL DA RESERVA DA BIOSFERA. Certificação em Turismo Sustentável. Conselho Nacional da Reserva da Biosfera da Mata Atlântica, com o apoio do Ministério do Meio Ambiente através da Secretaria de Bioiversidades e Florestas, UNESCO-Mab e Secretaria de Estado do Meio Ambiente do Estado de São Paulo - SMA. Caderno № 30, 2004. Disponível em http://www.rbma.org.br/rbma/pdf/caderno_30. Acesso: 07 de junho de 2017 as $16 \mathrm{~h}$.

CORIOLANO, Luzia Neide; LEITÃO, Claudia. Turismo, Cultura e desenvolvimento entre sustentabilidade e (in) sustentabilidades. Revista PASOS- Revista de Turismo y Patrimônio Cultural. V.06 № 3. Págs. 467-479. 2008.

ELKINGTON (1994) in SARTORI, Simone; LATRÔNICO, Fernanda; CAMPOS, Lucila M. S. Sustentabilidade e Desenvolvimento Sustentável. Revista Ambiente e Sociedade, São Paulo v. XVII n.1 P.1-22 Jan-mar 2014.

INSTITUTO ECOBRASIL. Acordo Mononk. Disponível em www.insititutoecobrasil.com Acesso: 10 de junho de 2017 as 11:00h.

JANUÁRIO (199-) apud OLIVEIRA, Junior Altino Bonfim de. A construção social do Ecoturismo como colonização do futuro: Um estudo de caso na Chapada dos Veadeiros. Tese (Doutorado)- Universidade Federal de Santa Catarina, Centro de Filosofia e Ciências Humanas, 2003.

LOBÔ, Monique. Hotels Brasil: Selo de Sustentabilidade. Agenda Bahia, 15/12/2014, última edição 07:47:02. Disponível em www.agendabahia.com ; acesso as 16:40 do dia 15 de maio de 2017.

OLIVEIRA, Junior Altino Bonfim de. A construção social do Ecoturismo como colonização do futuro: Um estudo de caso na Chapada dos Veadeiros. Tese (Doutorado)- Universidade Federal de Santa Catarina, Centro de Filosofia e Ciências Humanas, 2003.

PARQUE NACIONAL DA CHAPADA DOS VEADEIROS. Instituto Chico Mendes da Conservação da Biodiversidade: História, localização e atrativos do parque Nacional da Chapada dos Veadeiros. Disponível em www.icmbio.org.gov.br. Acesso 05 de junho de 2017 as 10 horas.

RUDZEWICZ, Laura; CASTROGIOVANNI, Antonio Carlos. Desenvolvimento do Turismo de Aventura em Parques Nacionais Brasileiros. In: I SEMINTUR- Seminário de Pesquisa em Turismo do Mercosul, 2003. Caxias do Sul- RS: Universidade de Caxias do Sul, 2003. P.1-10.

WEARING e NEIL, 2001 apud RUDZEWICZ, Laura; CASTROGIOVANNI, Antonio Carlos. Desenvolvimento do Turismo de Aventura em Parques Nacionais Brasileiros. In: I SEMINTUR- Seminário de Pesquisa em Turismo do Mercosul, 2003. Caxias do Sul- RS: Universidade de Caxias do Sul, 2003. P.1-10. 